\title{
Desenvolvimento de jogo digital educacional no RPG Maker MV para auxiliar no processo de ensino-aprendizagem de ortografia da Língua Portuguesa
}

\author{
Fabio Nunes Assunção ${ }^{1}$ \\ Nukácia Meyre Silva Araújoº
}

Programa de Pós-Graduação em Linguística Aplicada, Universidade Estadual do Ceará, Fortaleza, CE, Brasil

Resumo: Este artigo relata o desenvolvimento de um jogo digital, a ser utilizado como recurso didático para auxiliar no processo de ensino-aprendizagem de ortografia. A fundamentação teórica baseia-se nos estágios de aquisição da escrita (MOREIRA, 2009) e na relação entre letras e sons (MORAIS, 2008). O conteúdo didático do jogo foi elaborado em conjunto com uma professora de Língua Portuguesa e o jogo digital foi desenvolvido através do software RPG Maker MV. Os dados foram coletados através de sessões de jogos e de entrevistas com alunos do 50 ano do Ensino Fundamental de uma escola pública de Fortaleza/CE. A análise dos dados preliminares mostrou que o jogo digital foi bem aceito pelos alunos. Os dados mostram também uma série de aspectos que precisam ser aprimorados para a próxima versão do jogo digital educacional, como a dificuldade e a diversidade dos conteúdos e a interação entre o jogador e os elementos do próprio jogo.

Palavras-chave: Jogo digital; Ensino-aprendizagem; Ortografia.

Title: Development of educational digital game in RPG Maker MV to assist in the teaching and learning process of Portuguese Orthography

Abstract: This article reports the development of a digital game, to be used as didactic resource to assist in the process of teaching-learning of orthography. The theory is based on the stages of acquisition of writing (MOREIRA, 2009) and on the relationship between letters and sounds (MORAIS, 2008). The didactic content of the game was prepared in conjunction with a Portuguese Language teacher and the digital game was developed through RPG Maker MV software. Data were collected through game sessions and interviews with students of the 5th grade Elementary School of a public school in Fortaleza, Ceará, Brazil. Preliminary data analysis showed that the game was well accepted by the students. The data also show a number of aspects that need to be improved for the next version of the educational digital game, such as its difficulty and diversity of content and interaction between the player and the elements of the game itself.

Keywords: Digital game; Teaching and learning; Orthography.

\footnotetext{
${ }^{1}$ Doutor em Linguística Aplicada (Universidade Estadual do Ceará), Professor do Curso de Graduação em LetrasInglês da Universidade Estadual do Ceará. Orcid: https://orcid.org/0000-0001-7701-2358

E-mail: fabionunes77@gmail.com

2 Doutora em Educação (Universidade Federal do Ceará), Professora do Programa de Pós-graduação em Linguística Aplicada da Universidade Estadual do Ceará. Orcid: https://orcid.org/0000-0003-1951-0417

E-mail:nukacia@gmail.com
} 


\section{O potencial dos jogos digitais para a educação}

Os jogos digitais conquistaram um espaço importante na vida de crianças, jovens e adultos e hoje constituem um dos setores que mais cresce na indústria de mídia e entretenimento (SAVI; ULBRICHT, 2008). Com um faturamento multimilionário, os jogos digitais já assumiram um papel de destaque na cultura contemporânea, o que incentivou diversos pesquisadores a desenvolverem estudos para entender as razões pelas quais os jogos digitais são tão atraentes e quais impactos causam na vida das pessoas (KIRRIEMUIR; MCFARLANE, 2004).

Os jogadores permanecem longos períodos empenhados nos desafios propostos pelos jogos, e, consequentemente, consomem um tempo que poderia ser aproveitado em outras atividades, como o estudo, por exemplo. Isto gera reclamações entre pais e professores, que gostariam que seus filhos e alunos aplicassem nos estudos o mesmo nível de atenção e comprometimento dedicado aos jogos (KIRRIEMUIR; MCFARLANE, 2004).

Desviar o foco que muitos estudantes dão aos jogos para atividades educacionais não é fácil. Por esta razão, tem aumentado o número de pesquisas que tentam encontrar formas de unir ensino e diversão através do desenvolvimento de jogos digitais educacionais. Por proporcionarem práticas educacionais atrativas e inovadoras, através das quais o aluno pode aprender de forma mais ativa, dinâmica e motivadora, os jogos digitais educacionais podem se tornar auxiliares importantes do processo de ensino e aprendizagem (SAVI; ULBRICHT, 2008). No entanto, para serem utilizados com fins educacionais, os jogos digitais precisam ter objetivos de aprendizagem bem definidos, ou promover o desenvolvimento de estratégias ou habilidades para ampliar a capacidade cognitiva e intelectual dos alunos (GROS, 2003).

De forma geral, os componentes básicos dos jogos digitais são os seguintes: 1) o papel ou personagem do jogador; 2) as regras do jogo; 3) metas e objetivos; 4) quebracabeças, problemas ou desafios; 5) história ou narrativa; 6) interações do jogador; 7) estratégias; 8) feedback e resultados (SAVI; ULBRICHT, 2008). Entretanto, para serem utilizados como instrumentos educacionais, os jogos devem conter algumas características específicas que atendam às necessidades de aprendizagem. Deste modo, qualquer aplicativo educacional, incluindo os jogos digitais, deve possuir objetivos claramente pedagógicos e sua utilização deve estar inserida em um contexto de ensino baseado em uma metodologia que oriente o processo, através da interação, motivação e descoberta, facilitando a aprendizagem de um conteúdo (PRIETO et al., 2005). A seguir são elencados alguns benefícios que os jogos digitais educacionais podem trazer aos processos de ensino-aprendizagem:

a) Motivação: Os jogos educacionais demonstram capacidade para entreter ao mesmo tempo em que incentivam o aprendizado por meio de ambientes 
interativos e dinâmicos (SAVI; ULBRICHT, 2008). Conseguem provocar o interesse e motivam estudantes com desafios, curiosidade, interação e fantasia. Proporcionam também uma rica experiência estética visual e espacial, atraindo os jogadores para mundos fictícios que despertam sentimentos de aventura e prazer (MITCHELL; SAVILL-SMITH, 2004). Estes componentes de prazer e de diversão são importantes porque, com o aluno mais relaxado, normalmente há maior recepção e disposição para o aprendizado (PRENSKY, 2001). As metas e desafios que precisam ser vencidos mantêm os jogadores motivados e, em alguns casos, podem até recuperar o ânimo de quem perdeu o interesse pelo estudo (SAVI; ULBRICHT, 2008).

b) Auxílio ao aprendizado: Jogos digitais viabilizam a geração de elementos gráficos capazes de representar uma grande variedade de cenários. Podem auxiliar, por exemplo, o entendimento de ciências e de matemática quando se torna difícil manipular e visualizar determinados conceitos. Além disso, fazem com que o aluno tome decisões e o expõe a níveis crescentes de desafios para possibilitar uma aprendizagem através da tentativa e erro (MITCHELL; SAVILL-SMITH, 2004). Normalmente, desenvolvedores de jogos digitais colocam o usuário em um ambiente de aprendizagem e então aumentam a complexidade das situações e, conforme as habilidades melhoram, as reações do jogador se tornam mais rápidas e as decisões são tomadas com maior velocidade (KIRRIEMUIR; MCFARLANE, 2004). Muitos professores reconhecem que os jogos digitais contribuem também para o desenvolvimento de estratégias importantes para a aprendizagem, como resolução de problemas, raciocínio dedutivo e memorização (MCFARLANE et al, 2002). Outros benefícios incluem a melhoria do pensamento estratégico, melhoria das habilidades psicomotoras, desenvolvimento de habilidades analíticas e habilidades computacionais (MITCHELL; SAVILL-SMITH, 2004). Alguns jogos online, disputados em equipes, ajudam a aprimorar o desenvolvimento de estratégias em grupo e a prática do trabalho cooperativo (GROS, 2003).

c) Desenvolvimento de habilidades cognitivas: Jogos digitais promovem o desenvolvimento intelectual, já que, para vencer os desafios, o jogador precisa elaborar estratégias e entender como os diferentes elementos do jogo se relacionam (GROS, 2003). Também podem desenvolver várias habilidades cognitivas, como resolução de problemas, tomada de decisão, reconhecimento de padrões, processamento de informações, criatividade e pensamento crítico.

d) Experiência de novas identidades: Muitos jogos digitais oferecem aos jogadores experiências de imersão em outros mundos e a vivência de diferentes identidades. Através desta imersão, ocorre o aprendizado de competências e conhecimentos associados com as identidades dos personagens dos jogos (SAVI; 
ULBRICHT, 2008). Assim, num jogo em que o estudante controla um engenheiro, médico ou piloto de avião, ele estará enfrentando os problemas e dilemas que fazem parte da vida destes profissionais, assimilando conteúdos e conhecimentos referentes às suas atividades.

e) Socialização: Outra vantagem dos jogos educacionais é que eles podem servir como agentes de socialização, pois aproximam os alunos jogadores, de forma competitiva ou cooperativa, dentro do mundo virtual ou no próprio ambiente físico de uma escola. Em rede, com outros jogadores, os alunos têm a chance de compartilhar informações e experiências, expor problemas relativos aos jogos e ajudar uns aos outros, resultando num contexto de aprendizagem distribuída (SAVI; ULBRICHT, 2008).

f) Experiência: Crianças e jovens que jogam jogos digitais se tornam experientes no que o jogo propõe. Isso indica que jogos com desafios educacionais podem ter o potencial de tornar seus jogadores experientes nos temas abordados (SAVI; ULBRICHT, 2008)

Embora seja difícil encontrar em um único jogo todas as potencialidades apresentadas acima, procurou-se demonstrar como este tipo de mídia pode trazer uma série de benefícios ao ser utilizada como recurso didático em práticas de ensino.

\section{O desenvolvimento do jogo digital educacional}

Entre os jogos educacionais disponíveis, há muitos que são direcionados a diferentes aspectos do ensino da Língua Portuguesa. Para tal, um jogo digital se mostra particularmente adequado, já que os alunos em fase de aprendizagem estão também no processo de descoberta e utilização dos consoles $^{3}$ e computadores. Deste modo, o jogo digital educacional fala na "mesma língua" dos jovens alunos (KIRRIEMUIR; MCFARLANE, 2004).

A partir dos pressupostos apresentados sobre o desenvolvimento e o uso de jogos digitais educacionais, iniciou-se o desenvolvimento de um jogo digital educacional como recurso didático durante o processo de alfabetização em Língua Portuguesa, com o objetivo de facilitar a transição dos alunos da escrita alfabética para a escrita ortográfica. Com isso, buscou-se compreender melhor o processo de ensino-aprendizagem da ortografia através do uso do jogo digital.

O desenvolvimento do jogo seguiu as seguintes etapas: investigação das necessidades

\footnotetext{
${ }^{3}$ Console de jogo eletrônico é um microcomputador dedicado a executar jogos digitais de diversos gêneros, como jogos de tiro, jogos de ação, música e outros. Atualmente, os principais consoles são o Playstation 4, da Sony, e o Xbox One, da Microsoft.
} 
pedagógicas de uma professora de Língua Portuguesa; criação de um protótipo de jogo digital educacional; certificação do conteúdo didático do jogo através de pesquisa em banco de dados; coleta de dados com alunos através de sessões de jogo e entrevistas; análise dos dados.

O desenvolvimento de um jogo digital educacional justifica-se ao acrescentar dados ao conjunto de trabalhos que estudam o potencial educativo dos jogos digitais. Conforme discutido anteriormente, os jogos digitais podem funcionar como ferramentas pedagógicas, mas a sua efetividade depende ainda de análise e acompanhamento de resultados. Desse modo, quanto mais pesquisas forem realizadas para este fim, maior segurança terão os profissionais que farão uso dessas ferramentas.

Finalmente, destaca-se a criação de um jogo digital educacional que seja testado e acompanhado por professores e seus alunos, para produzir um exemplar que não apresente os problemas que tantos jogos educacionais possuem. Esse aspecto destaca o impacto social da empreitada, pois o desenvolvimento do jogo está diretamente associado às contribuições das professoras e dos alunos participantes. Isso resulta em um aumento da autoestima desses participantes, que se sentem parte integrante da própria criação do jogo. Além disso, futuros usuários do jogo desfrutarão de um produto elaborado de acordo com suas necessidades, e professores contarão com um recurso de qualidade e testado para utilizar em suas aulas.

\section{A base teórica para o conteúdo do jogo}

O foco do jogo é o de servir como objeto de aprendizagem, mais especificamente, como recurso didático a professores de Língua Portuguesa para auxiliar no processo de processo de ensino-aprendizagem da ortografia. Portanto, a abordagem teórica que fundamenta o desenvolvimento do conteúdo e da progressão do jogo baseia-se nos estudos de Moreira (2009) sobre os estágios da escrita, e Morais (2008) sobre as relações entre letras e sons.

Dentro do processo de aquisição da escrita ortográfica, Moreira (2009) estabelece o que chama de estágios e fases linguísticas da escrita infantil. Os estágios e fases da são apresentados no quadro a seguir: 
Quadro 1 - Estágios de escrita

\begin{tabular}{|l|l|}
\hline Estágio & $\begin{array}{l}\text { Utilização de desenhos para representar a realidade (algo ou alguém); evolução } \\
\text { Ios rabiscos conceptuais em precisão gradativa; surgimento do desenho } \\
\text { esquemático; início da percepção das letras como algo que representa o que o } \\
\text { adulto fala; uso de desenho para representação do conceito e de rabiscos para } \\
\text { representar a fala. }\end{array}$ \\
\hline $\begin{array}{l}\text { Estágio } \\
\text { grafemático }\end{array}$ & $\begin{array}{l}\text { Percepção de que a escrita do adulto não tem como caractere fundamental o } \\
\text { desenho; uso de traçados puros nas tentativas de escrita; percepção do caráter } \\
\text { arbitrário do sistema de escrita; ausência de compreensão de que a escrita } \\
\text { representa a fala; uso de rabiscos retos, curvos ou arredondados; utilização } \\
\text { combinadas das letras do nome próprio, sem relação aparente com o som; } \\
\text { utilização dos critérios quantitativos e qualitativos nas produções gráficas. }\end{array}$ \\
\hline $\begin{array}{l}\text { Estágio } \\
\text { fonográfico }\end{array}$ & $\begin{array}{l}\text { Subvocalização para monitorar o que está escrevendo; percepção e representação } \\
\text { dos sons salientes; expressão do desejo de escrever o que se fala; ausência de } \\
\text { compreensão do caráter linear da escrita; elaboração de um sistema próprio de } \\
\text { escrita; percepção de palavras escritas do mesmo modo; análise mais sistemática } \\
\text { da relação entre escrita e oralidade; percepção e representação de alguns fonemas } \\
\text { salientes; reconhecimento do caráter fonográfico sistemático da escrita; } \\
\text { consciência alfabética bem marcada; presença de conflitos quanto ao segmento } \\
\text { sonoro que está representado e sua letra correspondente; representação gráfica } \\
\text { mais fidedigna e sistemática. }\end{array}$ \\
\hline $\begin{array}{l}\text { Ruptura com o caráter sistemático da escrita, com uma hipótese fundada na } \\
\text { relação dos elementos discretos perceptíveis; contato com o imprevisto, o } \\
\text { assistemático, o arbitrário; a língua entra na esfera social. }\end{array}$ \\
\hline $\begin{array}{l}\text { Estágio } \\
\text { ortográfico }\end{array}$
\end{tabular}

Fonte: Adaptado de Moreira (2009)

Segundo Morais (2008), as letras e sons da Língua Portuguesa estabelecem as seguintes relações: correspondências fonográficas regulares (diretas, contextuais e morfológico-gramaticais) e irregulares. Para o autor,

[o] entendimento do que é regular e do que é irregular em nossa ortografia me parece fundamental para o professor organizar seu ensino. Se percebemos que os erros ortográficos têm causas distintas, podemos abraçar a ideia de que a superação de erros diferentes requer estratégias de ensino-aprendizagem diferentes. (MORAIS, 2008, p. 28)

Morais (2008) compreende, portanto, que há motivos diferentes para os diferentes desvios cometidos por alunos em processo de aquisição da escrita - processo esse que perdura por toda a vida, já que ninguém é capaz de dominar a totalidade da escrita de um idioma. O ideal seria, assim, identificar que tipo de desvio está ocorrendo para que se aplique uma estratégia eficaz de aprendizado. O quadro a seguir apresenta as correspondências propostas por Morais (2008). 
Quadro 2 - Correspondências fonográficas

\begin{tabular}{|l|l|}
\hline $\begin{array}{l}\text { Regulares } \\
\text { diretas }\end{array}$ & $\begin{array}{l}\text { Existe uma correspondência biunívoca entre letra e som. Estes casos são os mais } \\
\text { raros e podem ser representados pelas letras p, b, t, d, f, v e seus respectivos sons. }\end{array}$ \\
\hline $\begin{array}{l}\text { Regulares } \\
\text { contextuais }\end{array}$ & $\begin{array}{l}\text { É o contexto, na própria palavra, que define a letra a ser utilizada. Entre os } \\
\text { exemplos, encontram-se o uso de R ou RR em palavras como "rato", "porta", } \\
\text { "honra", "prato", "barata" e "guerra"; o uso de G ou GU em palavras como "garoto" } \\
\text { e "guerra"; o uso de E ou I no final de palavras que terminam "com som de I", } \\
\text { como em "perde" e "perdi"; o uso de M, N, NH ou para grafar todas as formas de } \\
\text { nasalização da Língua Portuguesa, como em "campo", "canto", "minha", "pão" e } \\
\text { "maçã"; entre outros. }\end{array}$ \\
\hline $\begin{array}{l}\text { Regulares } \\
\text { morfológico- } \\
\text { gramaticais }\end{array}$ & $\begin{array}{l}\text { A escrita segue uma regra ligada à categoria gramatical da palavra. Entre os casos, } \\
\text { pode-se incluir palavras como "portuguesa", "francesa" e demais adjetivos que } \\
\text { indicam o lugar de origem se escrevem com ESA no final; "beleza", "pobreza" e } \\
\text { demais substantivos derivados de adjetivos e que terminam com o segmento } \\
\text { sonora [eza] se escrevem com EZA; substantivos derivados que terminam com os } \\
\text { sufixos ÊNCIA, ANÇA e ÂNCIA, como em "ciência", "esperança" e "importância"; } \\
\text { Em flexões verbais, como "cantou", "bebeu", "partiu" e todas as outras formas da } \\
\text { terceira pessoa do singular do passado (perfeito do indicativo) se escrevem com U } \\
\text { no final; entre outros. }\end{array}$ \\
\hline $\begin{array}{l}\text { Irregulares } \\
\text { Diferentes letras podem representar diferentes sons, mas não há regras específicas } \\
\text { para a escrita correta, ou seja, não há um princípio fônico para determinar a } \\
\text { escrita, apenas a convenção. Como exemplo, o som / z / pode ser representado } \\
\text { por diferentes letras (s, z e x) na mesma situação de posição entre vogais (mesa, } \\
\text { certeza, exemplo). }\end{array}$ \\
\hline
\end{tabular}

Fonte: Adaptado de Morais (2008)

\section{O jogo "Aventura das Letras Mágicas"}

O recurso escolhido para o desenvolvimento do jogo digital educativo foi o software RPG Maker MV. A criação do protótipo evidenciou uma série de vantagens com relação à escolha do referido software. Primeiramente, O RPG Maker MV possibilitou o desenvolvimento do jogo sem a necessidade de conhecimentos em programação ou computação gráfica, dispensando a contratação de programadores. Além disso, os jogos desenvolvidos através do RPG Maker MV apresentam uma estética baseada em pixel art, uma forma de arte digital na qual as imagens são criadas ou editadas tendo como elemento básico os pixels. Esse estilo de arte foi utilizado nas primeiras gerações de jogos digitais e, dada a sua característica cartunesca, ainda se mantém presente em vários jogos até hoje. Finalmente, a produção do protótipo permite afirmar que, quando a versão final do jogo for desenvolvida, ela poderá ser disponibilizada de tal maneira que outros professores possam adaptá-lo às suas próprias necessidades e conteúdo.

A narrativa do jogo acontece em um universo de fantasia e gira em torno de fadas aprisionadas em cristais mágicos. Esse aprisionamento ocorre devido à disputa entre um 
feiticeiro maligno, chamado Oberon, e a rainha das fadas, Titânia. Oberon decide capturar as fadas em cristais mágicos para absorver seus poderes. O papel do jogador é o de libertar as fadas de dentro dos cristais, através das respostas certas dadas aos diferentes desafios de cada fase. Respostas corretas resultam na libertação das fadas, enquanto respostas erradas penalizam o jogador, diminuindo a sua pontuação. O jogador começa o jogo com cinco pontos, ou seja, ele só pode cometer, no máximo, cinco erros durante a partida. O jogo acaba de duas formas: com a vitória do jogador, ao libertar todas as fadas; ou com a sua derrota, ao responder cinco perguntas de forma errada e perder todos os seus pontos.

O jogo conta com quatro fases distintas - a Casa, a Fazenda, a Floresta e a Fortaleza. A Casa serve como um tutorial, ou seja, é um ambiente no qual o jogador aprende os comandos básicos do jogo e conhece a narrativa com a qual irá interagir. As fases seguintes apresentam, cada uma, desafios específicos, relacionados aos estágios de aquisição da escrita e às suas regularidades e irregularidades.

No início do jogo, são informados os conceitos básicos (clique, movimentação, digitação) e a narrativa. As informações são dadas ao jogador através de caixas de texto, que são acompanhadas por faixas de áudio.

Figura 1 - Tutorial (A Casa)

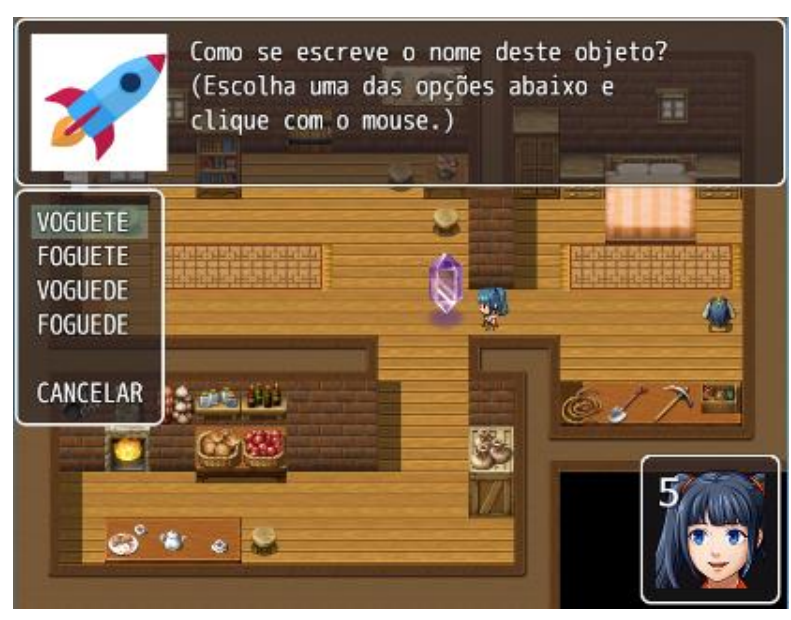

Fonte: elaborado pelo autor

Os textos são informados por uma narradora e pelos próprios personagens do jogo. No tutorial, há apenas um desafio, cuja escrita está relacionada a processos de correspondência fonográfica regular direta.

Após a conclusão dessa etapa, o jogador insere o próprio nome e salva o seu progresso pela primeira vez. A inclusão do nome e o salvamento do progresso são importantes para a geração do relatório de acertos e erros ao final da partida. 
Na primeira fase do jogo (A Fazenda), os desafios são similares ao apresentado no tutorial. Cada um dos cristais apresenta um desafio que consiste na escolha da palavra certa referente à ilustração apresentada.

Figura 2 - Fase 1 (A Fazenda)

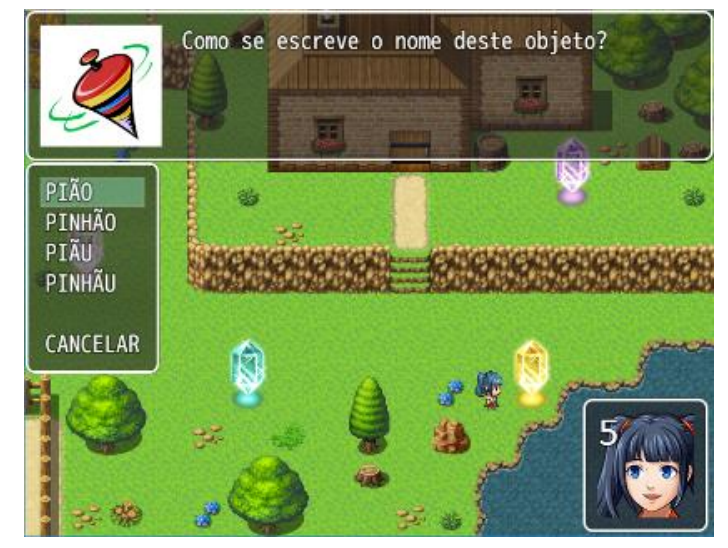

Fonte: elaborado pelo autor

É importante salientar que o uso de ilustrações no tutorial e na primeira fase está relacionado com o estágio de escrita icônica proposto por Moreira (2009). Os desafios dessa fase apresentam casos de correspondência fonográfica com regularidades contextuais, segundo Morais (2008).

O quinto desafio não está presente em um cristal, mas sim no enfrentamento de um "chefe de fase", na forma de um dos soldados do feiticeiro Oberon. Neste caso, surge o personagem Porcão da Mutação.

Figura 3 - Chefe da Fase 1 (A Fazenda)

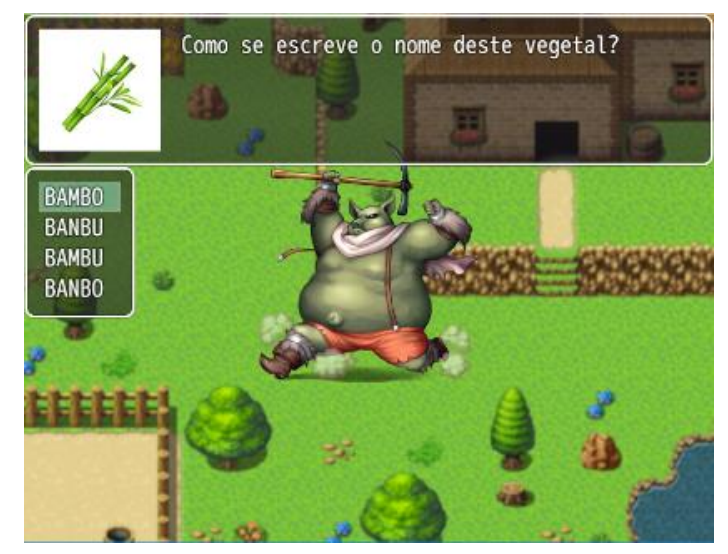

Fonte: elaborado pelo autor 
$\mathrm{Na}$ segunda fase, é apresentado um novo sistema de jogabilidade. Ao invés de escolher a forma correta de uma palavra, o jogador deve digitar a palavra de cada desafio após ouvi-la. Para isso, o jogador deve clicar em um dos cristais e escolher entre duas opções, conforme mostra a figura a seguir:

Figura 4 - Fase 2 (A Floresta)

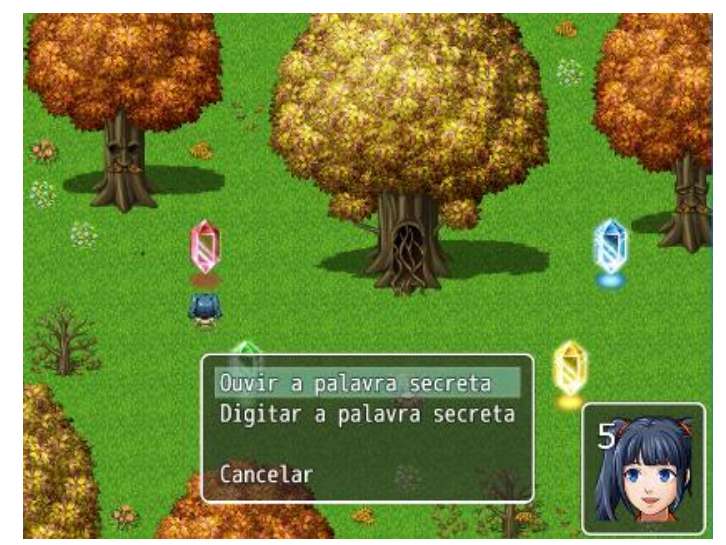

Fonte: elaborado pelo autor

Ao clicar na primeira opção, o jogador ouve a palavra a ser digitada. Ao escolher a segunda opção, surge uma caixa de texto, na qual o jogador deve digitar a palavra que acabou de ouvir. Este modelo de jogabilidade foi baseado no estágio de escrita fonográfica, proposto por Moreira (2009). O conteúdo das palavras de cada desafio é referente ao processo de correspondência fonográfica regular morfológico-gramatical (MORAIS, 2008).

O quinto e o sexto desafios não estão presentes em cristais, mas sim no enfrentamento de um "chefe de fase", na forma de um dos soldados do feiticeiro Oberon. Neste caso, surge o personagem Ogro do Pântano.

Figura 5 - Chefe da Fase 2 (A Floresta)

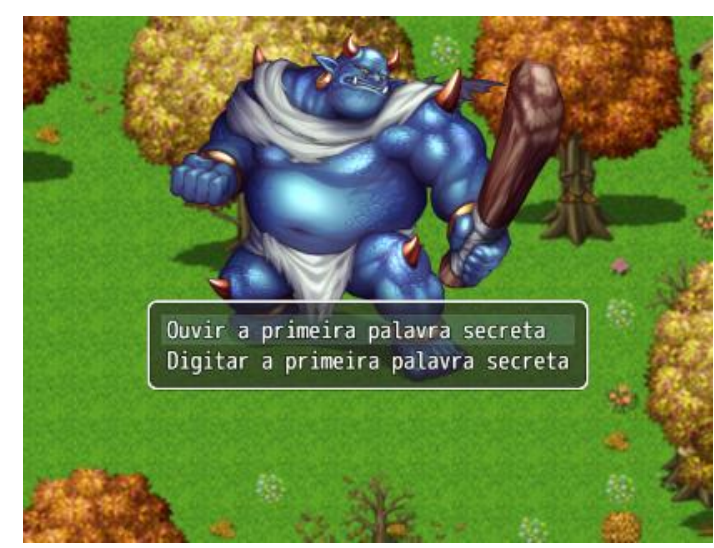

Fonte: elaborado pelo autor 
$\mathrm{Na}$ última fase, o jogador deve completar algumas palavras, escolhendo a letra correta. Ao clicar em uma das letras, o jogador escolhe para que palavra ela deve ir, completando o espaço vazio da letra que está faltando.

Figura 6 - Fase 3 (A Fortaleza)

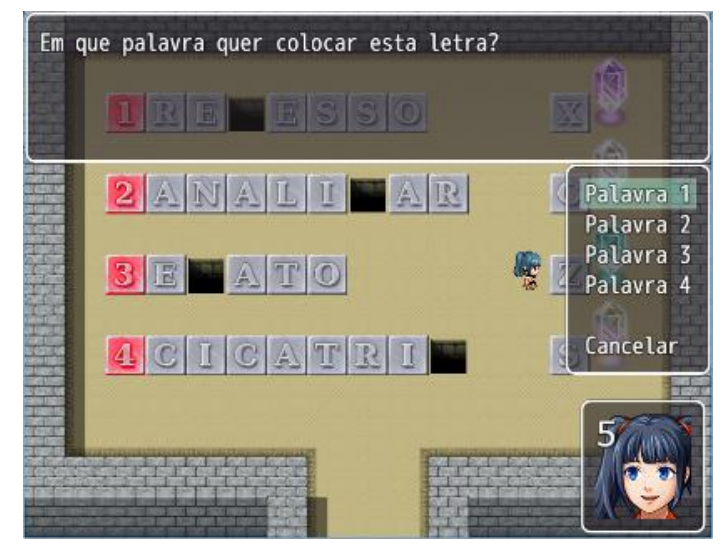

Fonte: elaborado pelo autor

Esse modelo de jogabilidade foi baseado no estágio de escrita ortográfica, proposto por Moreira (2009). As palavras desta fase foram escolhidas de acordo com alguns processos de correspondência fonográfica irregular (MORAIS, 2008).

O quinto, o sexto e o sétimo desafios não estão presentes em cristais, mas sim no enfrentamento de um "chefe de fase", na forma do próprio feiticeiro Oberon.

Figura 7 - Chefe da Fase 3 (A Fortaleza)

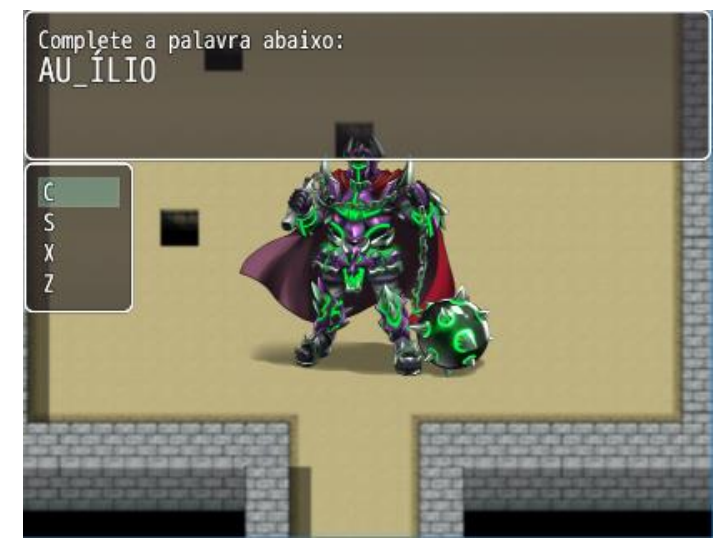

Fonte: elaborado pelo autor

Uma das características mais importantes do jogo é o relatório de acertos e erros, que surge ao final de cada partida. Esse relatório indica a quantidade de desafios cumpridos de forma certa ou errada em cada fase, o que pode apontar ao professor as dificuldades 
específicas de cada aluno quanto às relações entre sons e letras (MORAIS, 2008). O relatório pode ainda mostrar em que estágio e fase linguística encontra-se a criança (MOREIRA, 2009). Isso é possível devido ao fato de que cada fase do jogo está diretamente relacionada a estágios linguísticos específicos.

Figura 8 - Relatório de acertos e erros

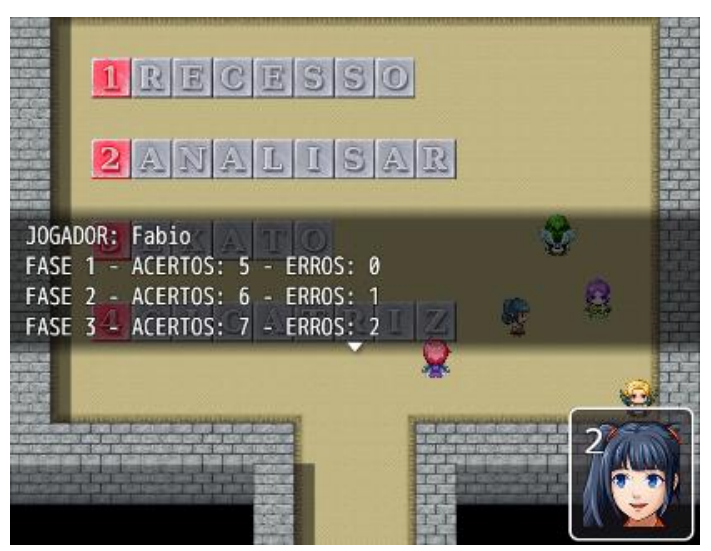

Fonte: elaborado pelo autor

De posse desses dados, o professor pode reforçar alguns conceitos de ortografia que ajudem os alunos com dificuldade a compreender certas relações entre letras e sons, bem como nivelar a turma para que os alunos encontrem-se em um mesmo estágio linguístico de aquisição da escrita.

\section{O uso do jogo por alunos do 5o ano do Ensino Fundamental}

Após a criação do jogo, o passo seguinte foi testá-lo com o seu público-alvo: cinco alunos do 5 ano do Ensino Fundamental. Esses alunos realizaram os testes e participaram de entrevistas sobre a sua utilização. Todos os procedimentos que ocorreram durante a coleta de dados da pesquisa foram aprovados pelo Comitê de Ética da Universidade Estadual do Ceará - UECE, o qual emitiu parecer (número 2.797.589) autorizando a realização da pesquisa, sob número CAAE 88969018.6.0000.5534.

As sessões de jogos ocorreram em uma escola pública na cidade de Fortaleza/CE. Conforme sugerido pela diretora, a pesquisa foi feita entre $14 \mathrm{~h}$ e $15 \mathrm{~h}$, horário de recreação dos alunos do 5o ano do Ensino Fundamental. Durante o período de recreação, foi possível realizar a coleta de dados com os alunos. Os alunos experimentaram o jogo em um computador portátil, um de cada vez. As sessões foram observadas e gravadas através de software de captura de vídeo. Durante a observação das sessões, foram feitas anotações a respeito de desempenho dos alunos-jogadores e de suas interações com o próprio jogo. 
Para guiar o processo de coleta de dados através da observação das sessões de jogo, o foco recaiu sobre os seguintes aspectos: interação entre o aluno-jogador e o equipamento (mouse e teclado); interação entre o aluno-jogador e o jogo em si, considerando a sua navegação pelo menu inicial, pelos cenários (fases) do jogo e com elementos específicos do jogo; a sequência de interação com os elementos do jogo; a quantidade de erros cometidos durante a partida e sua incidência nos diferentes desafios. Finalmente, após cada sessão, foi realizada uma breve entrevista com os alunos, cujas respostas foram anotadas e também gravadas em um smartphone.

O primeiro aluno a experimentar o jogo foi um menino de 11 anos de idade. A partida durou quarenta e cinco minutos, durante a qual o aluno apresentou certas dificuldades ao manusear o equipamento - o que pode ser justificado pelo fato de o aluno não possuir experiência com jogos ou computadores. O aluno leu e ouviu as instruções com atenção, mas ainda precisou de orientação em alguns momentos do jogo, principalmente na Fase 2 (A Floresta), na qual é necessário que o aluno-jogador digite a palavra que acabou de ouvir. Além disso, o aluno demorou um pouco a compreender que deveria sempre clicar com o mouse para passar pelas caixas de texto.

Ao longo da sessão de teste, o aluno cometeu um total de 18 erros, distribuídos em cinco tentativas - ou seja, o aluno chegou ao "Game Over" (Fim de Jogo) quatro vezes, antes de terminar todos os desafios. A quantidade de erros e de reinicializações gerou certa frustração no aluno e estendeu o tempo da sessão. Já nesta primeira sessão de teste, ficou evidente que o nível de dificuldade estava alto e que um novo sistema de recompensas e punições deveria ser elaborado. As demais sessões de coleta de dados confirmaram essa conclusão, conforme apresentado a seguir.

Um menino de 10 anos participou da segunda sessão, que durou trinta minutos. 0 aluno informou que já tinha certa experiência com jogos e com o uso de computadores. Ele não apresentou nenhuma dificuldade com o uso do equipamento e nem com os conceitos apresentados pelo jogo. Ao contrário dos demais alunos-jogadores, por exemplo, explorou as fases, clicando em diferentes objetos além dos cristais. Finalmente, foi o único aluno que não solicitou auxílio, interagindo diretamente com o jogo durante toda a sessão de teste.

O terceiro aluno a experimentar o jogo foi um menino de 11 anos de idade. A partida durou quarenta minutos, durante a qual o aluno apresentou mínimas dificuldades de interação, tanto com o equipamento quanto com o jogo em si, devido à familiaridade com jogos e computadores. Entretanto, foi o aluno que cometeu mais erros - um total de 27, distribuídos em nove partidas. Ao contrário dos demais, porém, o maior índice de erros deste aluno-jogador concentrou-se logo na Fase 1 (A Fazenda). 0 aluno cometeu múltiplos erros durante as escolhas das opções, chegando a clicar na mesma opção errada mais de uma vez.

Na Fase 2 (A Floresta), o aluno apresentou dificuldades em compreender as faixas de áudio e precisou ouvir cada uma das palavras muitas vezes. Chegou a digitar corretamente 
palavras diferentes das propostas pelo desafio. Por exemplo, em uma das tentativas, digitou "princesa" após ouvir a palavra "tristeza". Após o teste, ao conversar com a professora, descobriu-se que o aluno possuía, de fato, um leve problema de audição. Desse modo, o presente pesquisador pensou na possibilidade de alteração do desafio levando em consideração situações semelhantes com outros alunos.

O quarto aluno a jogar foi um menino de 11 anos de idade. A partida durou vinte minutos, na qual o aluno não apresentou maiores dificuldades de interação, mesmo tendo relatado não possuir familiaridade com computadores. Leu e ouviu as instruções com atenção e pediu auxílio apenas na Fase 1 (A Fazenda). A partir de então, interagiu com o jogo normalmente.

O que chamou a atenção neste caso foi a preocupação do aluno-jogador com a derrota. No entanto, ao entender que poderia reiniciar o jogo a partir da fase que havia realizado o processo de salvamento, demonstrou mais confiança durante as partidas. Foi o aluno que cometeu menos erros - 12 no total - e que reiniciou menos partidas, atingindo o Fim de Jogo apenas duas vezes. Em decorrência disso, foi quem apresentou menos demonstrações de frustração com o jogo.

Uma menina de 10 anos participou da quinta sessão, que durou trinta minutos. Com relação à interação com o equipamento, a aluna demonstrou algumas dificuldades, pois não era familiarizada com computadores, e tinha contato com jogos apenas através do console da irmã mais velha. Com relação à experiência de jogo, os maiores problemas surgiram em decorrência dos erros cometidos em cada desafio - totalizando 22 -, os quais resultaram em sete partidas.

Esta foi a aluna-jogadora que mais solicitou informações, tanto com relação à interação com o aparelho como com relação ao conteúdo dos desafios. Precisou ouvir as palavras da Fase 2 (A Floresta) muitas vezes, e só sentiu segurança para interagir com cada fase após algumas explicações.

Tendo em vista a experiência de cinco jogadores, o maior problema que o jogo apresentou está relacionado ao seu grau de dificuldade. O jogo mostrou-se muito difícil, levando todos os jogadores a perderem todos os "pontos de vida", tendo que reiniciar suas partidas, pelo menos duas vezes - e chegando a oito vezes no caso do Aluno 3. Isso ocorreu porque a quantidade de "pontos de vida (5)" se mostrou insuficiente. As muitas derrotas e a necessidade de reiniciar o jogo (mesmo que não do início, graças ao recurso de salvamento) levaram os alunos-jogadores a demonstrar frustração durante as partidas. Inclusive, um deles chegou a querer desistir do jogo.

Assim, a sugestão para garantir que as partidas não sofram com o excesso de dificuldade é a exclusão do conceito de Fim de Jogo e dos "pontos de vida". Ao invés disso, propõe-se, para a próxima versão do jogo, que as respostas certas atribuam uma pontuação ao jogador como forma de recompensa, e que as respostas erradas façam com que o "Cristal 
Mágico" referente àquele desafio simplesmente desapareça, impedindo que o jogador ganhe seus pontos. Desse modo, o jogador será capaz de progredir por todas as fases do jogo, em uma única partida, independentemente de quantos desafios respondeu de forma correta. Ao final, dependendo de sua pontuação, o jogador alcançará um final de jogo positivo ou negativo.

Outro problema, também relacionado à necessidade de reiniciar uma partida, é a veracidade das informações que constam no relatório de acertos e erros, gerado ao final de cada partida. O objetivo desse recurso era o de informar ao professor em que fase cada aluno cometeu seus erros, o que indicaria problemas que aquele determinado aluno ainda tem com um estágio específico da aquisição da escrita ou mesmo com algum tipo de relação entre letras e sons. No entanto, o relatório só registra os erros e acertos cometidos na última partida, desconsiderando a performance do jogador nas partidas em que se chegou ao Fim de Jogo. Assim, os resultados apresentados não condizem com a realidade da partida. $A$ sugestão proposta para este problema está associada à proposta ao problema anterior: como a próxima versão não contará mais com "pontos de vida", cada partida será única, do início ao fim, e os resultados mostrados no relatório serão verídicos.

Após cada sessão de jogo, os alunos-jogadores foram submetidos a uma breve entrevista, elaborada com o objetivo de recolher feedback imediato dos participantes sobre o jogo. As perguntas da entrevista foram elaboradas de modo a serem facilmente compreendidas pelos alunos e gerarem respostas simples, porém autênticas. A entrevista foi composta por 13 perguntas, conforme mostra o quadro a seguir:

Quadro 3 - Perguntas da entrevista após a sessão de jogo
1. O que você mais gostou no jogo?
2. Você conhecia o conteúdo?
3. Você aprendeu algo com o jogo?
4. Se sim, o que você aprendeu?
5. Você achou o jogo fácil, mediano ou difícil?
6. O jogo tinhas muitas ou poucas informações?
7. Em algum momento, você quis parar de jogar?
8. Você gostou de aprender com o jogo?
9. Você jogaria novamente?
10. Você jogaria novas fases?
11. O que você não gostou no jogo?
12. O que você acha que melhoraria o jogo?
13. Você entendeu a história?

Fonte: elaborado pelo autor 
A pergunta 1 (O que você mais gostou no jogo?) mostrou que a atenção dos alunos parece ter sido focada na variedade de desafios e no nível de dificuldade. Isso indica que, apesar de ter se mostrado difícil, os alunos consideraram o jogo desafiador o suficiente para permanecerem engajados.

As respostas à pergunta 2 (Você conhecia o conteúdo?) confirmam o nível de dificuldade dos desafios do jogo. A grande quantidade de erros cometidos pelos alunosjogadores fez com que alguns deles admitissem que ainda não dominavam muito bem o conteúdo. Os demais informaram que conheciam o conteúdo, mas, quando comparado com o desempenho de cada um durante as partidas, percebe-se que eles não dominaram a escrita correta, vindo a aprender com o próprio jogo, conforme pode ser observado nas respostas às perguntas 3 e 4 , a seguir.

As respostas das perguntas 3 (Você aprendeu algo com o jogo?) e 4 (Se sim, o que você aprendeu?) constatam que eles adquiriram conhecimento da escrita de certas palavras com o jogo. Todos afirmaram ter aprendido algo com a sessão e cada um apontou o que aprendeu, incluindo palavras como "PISCINA" (Aluno 2), "CICATRIZ" (Aluno 3), "CANAVIAL" e "TRISTEZA" (Aluno 5). Essas respostas reforçam o potencial do jogo desenvolvido para este artigo, pois além do entretenimento, os alunos estão, de fato, adquirindo conhecimento a partir dos desafios propostos.

A pergunta 5 (Você achou o jogo fácil, mediano ou difícil?) serviu para mostrar que o jogo demonstra um certo grau de desafio. A dificuldade foi considerada mediana pela maioria dos alunos-jogadores (Alunos 1, 4 e 5), e difícil pelos demais (Alunos 2 e 3 ). Entretanto, durante as observações das sessões de jogo, foi possível perceber que o nível de dificuldade causou o momento de Fim de Jogo para todos os alunos, múltiplas vezes. Isso gerou alguns momentos de frustração nos alunos-jogadores e a proposta de alteração de algumas mecânicas de jogabilidade pelo pesquisador.

As respostas à pergunta 6 (O jogo tinha muitas ou poucas informações?) evidenciam que os alunos-jogadores consideraram a quantidade de informações um pouco exagerada. Entretanto, percebeu-se, durante as sessões de jogo, que os alunos conseguiram interagir bem com o jogo em si, possivelmente em decorrência das instruções fornecidas durante o Tutorial (A Casa). Ainda sobre o Tutorial, deve-se ressaltar que as informações de jogabilidade e de narrativa foram intercaladas, na tentativa de gerar maior fluidez durante o aprendizado dos mecanismos do jogo.

A resposta que mais alertou o presente pesquisador quanto ao nível excessivo de dificuldade foi dada pelo Aluno 2 à pergunta 7 (Em algum momento, você quis parar de jogar?). $\mathrm{O}$ aluno-jogador respondeu que queria desistir do jogo na Fase 3 (A Fortaleza). $\mathrm{O}$ Aluno 2 não cometeu nenhum erro na Fase 1 (A Fazenda), mas cometeu muitos erros na Fase 2 (A Floresta), o que resultou em várias situações de Fim de Jogo. Mesmo tendo cometido menos erros na Fase 3, é possível que a frustração causada pelas muitas tentativas na fase anterior tenha desgastado a vontade de continuar jogando. Os demais alunos- 
jogadores afirmaram que não quiseram desistir do jogo, mas a observação das partidas revelou que eles também se frustraram com o nível de dificuldade.

As respostas das perguntas 8 (Você gostou de aprender com o jogo?), 9 (Você jogaria novamente?) e 10 (Você jogaria novas fases?) revelaram que o jogo foi capaz de agradar a todos os participantes. Todos gostaram de aprender através do jogo e todos jogariam novamente, inclusive novas fases.

As perguntas 11 ( $O$ que você não gostou no jogo?) e 12 (O que você acha que melhoraria o jogo?) tiveram como objetivo encontrar pontos negativos e de melhora, a partir da impressão direta dos próprios participantes. Dois deles (Alunos 1 e 2) não aprovaram os "chefes de fase", enquanto o Aluno 3 não gostou particularmente do nível de dificuldade da Fase 3 (A Fortaleza). Esse retorno dos alunos-jogadores é essencial para a melhoria dos elementos do jogo. Assim, foi confirmada a necessidade de equilibrar os desafios do jogo com a proposta de entretenimento, para deixar a experiência do jogo prazerosa e estimulante.

Finalmente, a pergunta 13 (Você entendeu a história?) pretendeu verificar o nível de complexidade da narrativa proposta pelo jogo. Todos os alunos compreenderam a narrativa, mesmo que parcialmente (Aluno 3).

Durante as sessões de jogos e entrevistas, foram observados padrões de interação entre os alunos participantes e o jogo. Essa observação começou no momento em que cada aluno teve contato com o dispositivo (um notebook). De imediato, percebeu-se que alguns alunos tiveram dificuldades em operar o mouse, desconhecendo, por exemplo, o conceito de duplo clique. Esse fenômeno pode ser explicado, possivelmente, pela falta de experiência dos alunos com o uso de computadores e/ou notebooks. Talvez os alunos da faixa etária entre 10 e 11 anos já estejam começando a utilizar com mais frequência os dispositivos móveis, tais como tablets e smartphones. Além disso, alguns alunos tiveram dificuldade também em acompanhar as instruções do jogo, clicando de forma errática, pulando as caixas de texto. Mesmo com os problemas apontados, ainda foi possível perceber que, de modo geral, os alunos conseguiram utilizar o jogo e lidar com o dispositivo.

\section{Considerações finais}

A participação dos alunos e da professora mostrou-se imprescindível para o desenvolvimento do jogo aqui reportado. A colaboração da professora foi o que delimitou, desde o início, o objetivo do jogo, baseado em suas próprias indagações quanto ao fenômeno da aprendizagem da escrita ortográfica. A troca de ideias com a professora foi bastante produtiva, pois, da mesma forma que o pesquisador se interessou pelo conteúdo e pelo desafio, a professora se interessou pelo método e pela pesquisa. 
A participação dos alunos pode ser descrita como fundamental, por várias razões. As crianças normalmente reagem de forma natural às situações do dia-a-dia. Isso leva a crer que as reações ao jogo, as ações tomadas durante as sessões de jogo e, principalmente, as respostas às entrevistas podem ser consideradas todas autênticas, o que garante a validade da pesquisa. Além disso, pode-se afirmar que a experiência de apresentar o jogo e receber feedback imediato fez com que o pesquisador já começasse a pensar em melhorias para a nova versão no jogo, no momento em que os alunos o estavam experimentando. Saber, por exemplo, que os desafios foram considerados difíceis, leva à reflexão de uma adequação do conteúdo didático às reais necessidades de aprendizagem dos alunos, o que será feito, juntamente com a professora, para a próxima versão do jogo. Por outro lado, saber que os alunos retornariam ao jogo, inclusive sugerindo a inclusão de mais fases, faz com que se pense que, apesar de ainda necessitar de melhorias, a estrutura básica do jogo está com o seu desenvolvimento no caminho certo.

É possível afirmar, portanto, que as contribuições de professores e alunos durante o desenvolvimento de um jogo digital educacional garantem que o produto final do processo esteja adequado às reais necessidades de seus usuários, além de contarem com conteúdo didático autêntico e baseado em aportes teóricos válidos.

Os dados mostraram que o jogo apresenta muitas características que o enquadram como um recurso didático eficiente, embora ainda haja espaço para melhorias. Os aspectos de jogabilidade (PRENSKY, 2001) parecem estar adequados, pois o jogo informa com clareza os seus objetivos e instruções e dá feedback constante ao jogador. Essas informações puderam ser confirmadas durante as sessões de jogos, das quais poucos foram os problemas que surgiram desse aspecto. $O$ jogo pode ainda ser reutilizado, utilizado por diferentes jogadores em um mesmo dispositivo, e é facilmente adaptável a diferentes níveis de escolaridade.

Durante as sessões de jogos e entrevistas, foram observados ainda padrões de interação entre os alunos participantes e o jogo. Essa observação começou no momento em que cada aluno teve contato com o dispositivo. De imediato, percebeu-se que alguns alunos tiveram dificuldades em operar o mouse. Esse fenômeno pode ser explicado, possivelmente, pela falta de experiência dos alunos com o uso de computadores. Talvez os alunos da faixa etária entre 10 e 11 anos já estejam começando a utilizar com mais frequência os dispositivos móveis, tais como tablets e smartphones.

Espera-se que o presente trabalho possa gerar frutos produtivos para as áreas de alfabetização e objetos de aprendizagem. Mas, acima de tudo, espera-se que o jogo possa ser usado efetivamente por professores e alunos e que cumpra o seu papel como recurso didático para o ensino-aprendizagem de ortografia. 


\section{Referências}

GROS, B. The impact of digital games in education. First Monday. v. 8, n. 7, jul. 2003. Disponivel em: <https://www.mackenty.org/images/uploads/impact_of_games_in_ education.pdf>. Acesso em jun. 2019.

KIRRIEMUIR, J.; MCFARLANE, A. Literature Review in Games and Learning. Bristol: Futurelab, 2004. Disponível em: <https://hal.archives-ouvertes.fr/hal-00190453/document>. Acesso em jun. 2019.

MCFARLANE, A.; SPARROWHAWK, A.; HEALD Y. Report on the educational use of games: An exploration by TEEM of the contribution which games can make to the education process. $2002 . \quad$ Disponível em: <http://questgarden.com/84/74/3/091102061307/files/teem_gamesined_full.pdf>. Acesso em jun. 2019.

MITCHELL, A.; SAVILL-SMITH, C. The use of computer and video games for learning: A review of the literature. Londres: Learning and Skills Development Agency (LSDA), 2004.

MORAIS, A. G. Ortografia: ensinar e aprender. 4 ed. São Paulo: Ática, 2008.

MOREIRA, C. M. O estatuto da sílaba na aprendizagem da leitura: comparando o percurso de crianças e adultos. 2009. 292f. Tese (Doutorado) - Programa de Pós-graduação em Letras e Linguística, Universidade Federal da Bahia, Instituto de Letras, Salvador, 2009.

PRENSKY, M. Digital game-based learning. New York: McGraw-Hill, 2001.

PRIETO, L. M.; TREVISAN, M. C. B.; DANESI, M. I.; FALKEMBACH, G. A. M. Uso das Tecnologias Digitais em Atividades Didáticas nas Séries Iniciais. Renote: Revista Novas Tecnologias na Educação. Porto Alegre, v. 3, n. 1, p. 1-11, mai. 2005. https://doi.org/10.22456/1679$\underline{1916.13934}$

SAVI, R.; ULBRICHT, V. R. Jogos digitais educacionais: benefícios e desafios. Novas Tecnologias na Educação. CINTED-UFRGS. v. 6 n. 2, dez. 2008. https://doi.org/10.22456/1679$\underline{1916.14405}$

Recebido em: 09/06/2019

Aceito em: 22/10/2019 